\title{
O Pensamento Computacional na Compreensão de Problemas do Cotidiano Feminino para o Letramento em Programação
}

\author{
Vânia Silvares Marquiori'1, Márcia Gonçalves de Oliveira' ${ }^{1}$ \\ ${ }^{1}$ Instituto Federal de Educação, Ciência e Tecnologia do Espírito Santo \\ vania.ifes@gmail.com, clickmarcia@gmail.com
}

\begin{abstract}
Starting from the problem of female retraction of computer science, this paper presents a proposal, still without experience, unplugged workshops for the development of Computational Thinking through workshops that deal with the problems of female feminine daily life using active methodologies for elementary school girls of a public school. For these workshops, one of the principles of Professional and Technological Education will be used, which refers to an articulation between theory and practice, at the development of activities that involve the pillars of Computational Thinking as a strategy to start the programming literacy and thus arouse the girls' interest in the area.
\end{abstract}

Resumo. Partindo da problemática de retração feminina da ciência da computação, este trabalho apresenta uma proposta, ainda sem experiência, de oficinas desplugadas para o desenvolvimento do Pensamento Computacional através de oficinas que tratem dos problemas do cotidiano feminino através de metodologias ativas para meninas do ensino fundamental de uma escola pública. Para essas oficinas será utilizado um dos princípios da Educação Profissional e Tecnológica, que se refere a articulação entre teoria e prática, no desenvolvimento de atividades envolvendo os pilares do Pensamento Computacional como estratégia para iniciar o letramento em programação e assim, despertar o interesse de meninas pela área.

\section{Introdução}

A tecnologia, assim como outros acontecimentos, têm provocado mudanças no mundo do trabalho. Outra mudança no mundo do trabalho tem sido a conquista de espaço pelas mulheres, e, muito embora esse ingresso represente conquistas para o universo feminino, o mercado ainda se encontra dominado por homens quando se trata do desenvolvimento de atividades automatizadas [Antunes 2009]. De acordo com a ONU(Organização das Nações Unidas)1 as mulheres estão fora daqueles trabalhos gerados pela revolução digital, ou seja, encontram-se excluídas da grande maioria das atividades dessa nova sociedade.

Um dos fatores que contribuem para a segregação de gênero nas atividades tecnologicamente mais desenvolvidas do mundo do trabalho tem origem desde a escolha da carreira ou profissão, como no caso das carreiras ligadas à ciência da computação, por exemplo, que ainda é majoritariamente masculina desde o ingresso na universidade [Nunes 2015; Lima 2013].

\footnotetext{
${ }^{1}$ https://nacoesunidas.org/onu-defende-aumentar-participacao-de-mulheres-em-ciencia-e-tecnologia/.
} 
Com as mudanças tecnológicas e na sociedade, novos problemas estão sempre surgindo em função do atendimento de novas necessidades, demandando profissionais capazes de conceber tais soluções. Para Saviani et al. [1994] com o domínio tecnológico no mundo do trabalho, a escola precisa acompanhar essa perspectiva buscando generalizar as tecnologias. Dessa forma, tais mudanças devem fazer parte do meio educacional, pois homens e mulheres necessitam se adaptar aos novos requisitos como a autonomia intelectual e à resolução de problemas [Brasil 2012], cada vez mais presentes no mundo do trabalho.

Dentre as ferramentas que têm sido utilizadas para estimular a criticidade e a capacidade de solucionar problemas está o Pensamento Computacional(PC), advindo da Ciência da Computação e preceituado por Wing [2016, p.4] como "uma forma para seres humanos resolverem problemas". Ainda de acordo com a autora o PC é uma ferramenta de transformação de um problema complexo em um problema de fácil compreensão, com possibilidades perceptíveis de solução[Wing 2016], corroborando com a visão de Ribeiro; Foss e Cavalheiro[2017] de que essa ferramenta pode ser utilizada na busca por soluções de quaisquer problemas, estando estes relacionados ou não a ciência da computação.

Dessa forma, a proposta deste trabalho é ofertar ao público feminino, das séries finais do ensino fundamental, oficinas com problemas cotidianos utilizando metodologias ativas e pensamento computacional para suas resoluções de formas teórica e prática, como meio de estimular sua criticidade e participação ativa na sociedade. Podendo ser uma possibilidade de despertar o interesse dessas meninas, e assim, contribuir para diminuição da desigualdade de gênero nas atividades tecnológicas do mundo do trabalho.

O trabalho se caracteriza como um extensão do trabalho intitulado "Letramento de Meninas em Programação através do Pensamento Computacional para Compreensão de Problemas" "apresentando um aprimoramento da temática das oficinas em relação ao contexto social do público da ação como ponto de partida para disseminação do PC. A organização encontra-se da seguinte maneira, além desta seção: a segunda, terceira e quarta seções apresentam a revisão de literatura e trabalhos relacionados ao tema. $\mathrm{Na}$ quinta seção encontra-se a programação metodológica planejada para as oficinas. E na última seção encontram-se expostos as possíveis conclusões e pretensões quanto aos resultados deste trabalho.

\section{Pensamento Computacional e a Educação Profissional}

"O pensamento computacional inclui uma série de ferramentas mentais que refletem a vastidão do campo da ciência da computação"[Wing 2016, p. 2] que permite aos seres humanos resolverem problemas em uma infinidade de situações, tendo estes problemas relação direta ou não com a ciência da computação [Ribeiro; Foss e Cavalheiro 2017].

O pensamento computacional é composto de quatro pilares, a saber: Decomposição, Reconhecimento de Padrões, Abstração e Algoritmos. A decomposição tem como objetivo fragmentar um problema, em problemas menores, para que seja possível, ou que fique alcançável sua resolução. O reconhecimento de padrões relaciona um problema a resolução para outros problemas similares. A abstração trata de elencar

\footnotetext{
${ }^{2}$ Uma versão preliminar e resumida deste trabalho foi apresentada no no $13^{\circ}$ Women in Information Technology do Congresso Brasileiro da Sociedade Brasileira de Computação.
} 
características essenciais de um problema, excluindo os supérfluos[Brackmann 2017]. E por último os algoritmos que são definidos como uma sequência finita de passos para resolver um problema[Lopes e Garcia 2002], ou de problemas menores derivados da decomposição de um problema maior[Brackmann 2017].

Sendo assim, pensar como um profissional da ciência da computação está além da capacidade de programar[Wing 2016], implica ser criativo e dinâmico na resolução de problemas, que não são privilégios de cientistas, apenas.

Diante das definições, e de como encontram-se as demandas sociais e do mundo do trabalho, pode-se pressupor que o pensamento computacional contribui para a aprendizagem da vida em sociedade, pois provoca o desenvolvimento de habilidades fundamentais, caracterizadas por Wing[2016 p. 4] como "algo que todo ser humano deve saber para atuar na sociedade moderna", levando em conta também, os diversos problemas que permeiam a humanidade, ansiando por soluções.

Partindo do pressuposto que o pensamento computacional trabalha habilidades que contribuem de muitas maneiras na implementação de práticas pedagógicas que tenham como finalidade o desenvolvimento dos novos requisitos como a autonomia intelectual e a resolução de problemas[Brasil 2012], toma-se a liberdade, neste trabalho, de relacionar a utilização do pensamento computacional aos preceitos da Educação Profissional e Tecnológica, no sentido de formar cidadãos críticos, capazes de compreender a dinâmica social, se adequando de forma consciente dentro do processo de ensino aprendizagem.

\section{Diferenças de Gênero no Mundo do Trabalho}

De acordo com Pinsky e Pedro[2012], vários obstáculos têm sido vencidos pelas mulheres, a fim de que possam ingressar na educação formal. No entanto, tais conquistas têm tido como pano de fundo o ingresso na educação pelas mulheres apenas para colaborar com sua "missão de mãe", com objetivo de participar na educação de filhos. Sendo o processo educativo estendido às mulheres com objetivos sociais muito diversos do que prega o caráter emancipatório da educação [Andrade e Neto 2015], que trata do desenvolvimento de amplas e variadas capacidades do ser humano.

A divisão sexual do trabalho guarda relação com o papel da mulher no processo reprodutivo, e também com as necessidades do mercado, que acabam por ditar quais espaços serão ocupados por mulheres, uma vez que a própria sociedade a faz enxergar, muitas vezes sua atividade extra domiciliar como passageira, e portanto, sem necessidade de investimento em uma carreira[Andrade e Neto 2015].

O exercício profissional da mulher, ainda hoje, encontra-se estreitamente ligado a um papel secundário imposto pela sociedade, que consistia em cuidar da educação dos filhos, dos doentes, entre outras atividades. Tal fato se reflete na grande parte das mulheres trabalhadoras mais qualificadas estarem atuando no magistério, na enfermagem e no serviço social, muito embora algumas estejam desbravando profissões socialmente caracterizadas como masculinas[Andrade e Neto 2015, p. 15].

Nesse contexto, a ciência da computação é mais uma profissão marcada pelos preceitos sociais como masculina, uma vez que possui como maioria atuante, o público masculino [Nunes 2015; Lima 2013]. Mas a própria história da profissão se encarrega de mostrar que Ada Byron - Lady Lovelace[Toole 1998], uma mulher, é reconhecida como a primeira programadora do mundo, levando a confirmar que a programação bem 
VIII Congresso Brasileiro de Informática na Educação (CBIE 2019)

Anais dos Workshops do VIII Congresso Brasileiro de Informática na Educação (WCBIE 2019)

como as atividades dela decorrentes não são apenas para homens.

Uma iniciativa importante que convém destacar é o apoio a Agenda 2030, dado pela ONU Mulheres(Organização das Nações Unidas) ${ }^{3}$ que traz o desafio intitulado "Por um Planeta 50-50 em 2030: um passo decisivo pela igualdade de gênero", abarcando a luta contra as desigualdades de gênero numa perspectiva ampla, incluindo também as condições de formação e acesso mais igualitário ao mundo do trabalho.

\section{Trabalhos relacionados}

A carência de profissionais nas áreas ligadas à Ciência da Computação se deve aos grandes índices de evasão dos ingressantes nesta carreira, e estes índices estão diretamente relacionadas às deficiências em conhecimentos básicos, como Português e Matemática, por exemplo, conforme Paula, Piva Jr e Freitas [2009].

As deficiências desses conhecimentos básicos dificultam a permanência dos estudantes no curso pois antes de programar efetivamente, o sujeito do processo precisa se familiarizar com o código, pois a complexidade da linguagem de programação demanda a combinação de várias habilidades cognitivas para sua aprendizagem [Oliveira, Nogueira e Oliveira 2015].

Diante dessa carência de profissionais que afeta o mercado de trabalho diretamente, algumas iniciativas têm sido feitas no sentido de aproximar a linguagem de programação e o pensamento computacional de práticas pedagógicas cotidianas. Um exemplo é o portal Programaê ${ }^{4}$, que tem como objetivo aproximar a programação da realidade de jovens e crianças brasileiros. Outra iniciativa importante é o Projeto Letramento em Programação $o^{5}$ do Instituto Ayrton Senna, voltado para escolas de ensino fundamental que tem como objetivo preparar crianças para os novos desafios da sociedade diante das mudanças tecnológicas.

No campo científico, alguns trabalhos versam sobre iniciativas que utilizam o pensamento computacional como estratégia de ensino aprendizagem. Entre eles podemos citar o trabalho de Schoeffel et al. [2015], que trata de uma experiência de sucesso no que diz respeito ao engajamento e resultado de alunos que foram submetidos a um curso que trabalhou conceitos de programação através do pensamento computacional, incluindo atividades desplugadas, e de como os conteúdos abordados despertaram o interesse desses alunos.

O trabalho de Queiroz e Santos [2017] discute que a aplicabilidade da linguagem de programação para o desenvolvimento do pensamento computacional tem permeado e contribuído para a Educação Básica, onde vem sendo empregado de maneira interdisciplinar. $O$ trabalho mostra ainda que a utilização de tecnologias auxilia no desenvolvimento do pensamento computacional, e ao trabalhar outras áreas/disciplinas e programação, ocorre contribuição mútua, onde um conhecimento coopera para a compreensão do outro e vice versa.

Quanto ao incentivo de meninas para a área citam-se dois trabalhos: o primeiro de autoria de Gomes et. al [2014] que mostra a utilização do Scratch para o ensino de programação para meninas nas disciplinas de física, matemática e química, com

\footnotetext{
${ }^{3}$ http://www.onumulheres.org.br/planeta5050-2030/

4 http://programae.org.br/

5 https://institutoayrtonsenna.org.br/content/institutoayrtonsenna/pt-br/radar/letramento-em-programacaorecebe-chancela-da-sociedade-brasileira-de-computacao.html
} 
separação da teoria e da prática. O outro trabalho, cuja autoria é de Ramos et al.[2015] narra a utilização da ferramenta MIT App Inventor, cujo objetivo é proporcionar a criação de aplicativos por pessoas sem experiência em programação, para ensinar/incentivar meninas a criar aplicativos para smartphone.

Com o desenvolvimento tecnológico, o ensino de programação tem caminhado para a Educação Básica, com objetivo de desenvolver habilidades computacionais, que são úteis na motivação e aprendizado de programação, bem como no desenvolvimento de novas habilidades requeridas nas demais ciências em virtude das mudanças no cenário social[Blatt; Becker e Ferreira 2017].

\section{Metodologia}

A proposta das oficinas consiste em observar o desenvolvimento de meninas que estejam cursando regularmente o segundo ciclo do ensino fundamental de uma escola pública do município de Nova Venécia-Es, objetivando o desenvolvimento de oficinas de pensamento computacional como forma de iniciação a programação desplugada, vinculado ao Projeto Corte de Lovelace, um projeto parceiro do Programa Meninas Digitais da Sociedade Brasileira de Computação (SBC) ${ }^{6}$.

As atividades das oficinas foram planejadas com base em metodologias de aprendizagem ativas, mais especificamente, a aprendizagem baseada em problemas, considerando que o público alvo será envolvido no processo, propiciando a participação ativa do sujeito da aprendizagem em todo o processo de resolução de problemas que guardem relação com seu universo.

A aprendizagem baseada em problema é uma metodologia ativa que "utiliza situações problema como ponto de partida para a construção de novos conhecimentos"[Filatro e Cavalcanti 2018, p. 32]. Assim, os problemas serão direcionados a soluções baseadas na metodologia do pensamento computacional, e trabalharão as habilidades de compreensão a partir dos próprios conteúdos básicos de programação [Antunes 2001].

A ideia é trabalhar com problemas simples, que estejam presentes no cotidiano das meninas, como forma de significar a absorção das novas formas de conceber problemas e de resolvê-los, nas dimensões teórica, explorando como elas resolveriam o problema, através da escrita de algoritmos(passo a passo). E após esse primeiro processo, solucionar o problema em sua dimensão prática, executando a solução encontrada, seguindo o algoritmo, numa tentativa de estimular a compreensão das duas faces de aprendizagem, refletindo sobre erros e acertos de suas abstrações e como modificar para alcançar os resultados esperados.

Dentro das oficinas de programação desplugada, a proposta de aplicação dos conteúdos terá como balizadores os pilares do pensamento computacional e a compreensão, estando programado conforme a Tabela 1 a seguir.

\footnotetext{
${ }^{6}$ Meninas Digitais: $\underline{\text { http://meninas.sbc.org.br/. }}$
} 
VIII Congresso Brasileiro de Informática na Educação (CBIE 2019)

Anais dos Workshops do VIII Congresso Brasileiro de Informática na Educação (WCBIE 2019)

Tabela 1. Oficinas de Pensamento Computacional

\begin{tabular}{|c|c|c|c|}
\hline Oficina & $\begin{array}{l}\text { Carga } \\
\text { horária }\end{array}$ & Objetivos & Estratégia de Letramento \\
\hline $\begin{array}{l}\mathrm{PC}^{*} \\
\text { Confeitado }\end{array}$ & 3 horas & $\begin{array}{l}\text { Trabalhar os pilares } \\
\text { do PC*: Algoritmo, } \\
\text { abstração e } \\
\text { decomposição, desta } \\
\text { forma: } \\
\text { a) Escrever um } \\
\text { algoritmo de como } \\
\text { preparar um bolo; } \\
\text { b) Escrever um } \\
\text { algoritmo de como } \\
\text { confeitar um bolo; } \\
\text { c) Atividade prática } \\
\text { de confeitar o bolo. }\end{array}$ & $\begin{array}{l}\text { Para esta oficina serão levados todos os materiais } \\
\text { necessários para confeitar o bolo, incluindo um bolo já } \\
\text { pronto para que as meninas possam colocar em prática um } \\
\text { dos algoritmos que escreveram. E ao final, será feita uma } \\
\text { comparação entre a ficha que escreveram o algoritmo de } \\
\text { confeitar o bolo inicialmente, com os passos seguidos, } \\
\text { informando de modificaram algo para que o bolo chegasse } \\
\text { ao resultado esperado, como forma de averiguar a } \\
\text { compreensão dos passos abstraídos e posteriormente } \\
\text { colocados em prática. }\end{array}$ \\
\hline $\begin{array}{l}\mathrm{PC}^{*} \\
\text { Maquiado }\end{array}$ & 4 horas & $\begin{array}{l}\text { Trabalhar os pilares } \\
\text { do PC*: Algoritmo, } \\
\text { abstração, } \\
\text { decomposição e } \\
\text { reconhecimento de } \\
\text { padrões desta forma: } \\
\text { a) Escrever um } \\
\text { algoritmo(tutorial) de } \\
\text { como fazer uma } \\
\text { maquiagem simples; } \\
\text { b) Executar o } \\
\text { tutorial(algoritmo) } \\
\text { com as colegas. }\end{array}$ & $\begin{array}{l}\text { O objetivo é propor um desafio para as alunas da seguinte } \\
\text { forma: como montar um tutorial de maquiagem similar } \\
\text { aos vistos no Youtube. Pretende-se dividir as alunas, entre } \\
\text { três a quatro grupos, sendo o ideal de três pessoas por } \\
\text { grupos, para que seja possível o revezamento de forma } \\
\text { que todas que queiram, possam ser maquiadas pelas } \\
\text { colegas, que será também uma forma de motivação para } \\
\text { participação. Em cada grupo deverá ter: uma pessoa } \\
\text { responsável por fazer as anotações dos passos a serem } \\
\text { seguidos; outra pessoa responsável por conferir e seguir os } \\
\text { passos anotados; enquanto a outra pessoa que será } \\
\text { maquiada; } \\
\text { Os materiais, tais como: batons, sombra, pincéis, algodão } \\
\text { demaquilante e outros, serão levados para que as alunas } \\
\text { possam efetivar a proposta. } \\
\text { A ideia é chegar ao final da oficina com um tutorial escrito } \\
\text { dos passos a serem seguidos para fazer a maquiagem. } \\
\text { Como forma de averiguar a absorção do pensamento } \\
\text { computacional a ideia é trabalhar os conceitos de entrada, } \\
\text { processamento e saída, depois das meninas terem que } \\
\text { utilizar as habilidades de abstração, decomposição e } \\
\text { escrita de algoritmo. }\end{array}$ \\
\hline $\begin{array}{l}\mathrm{PC}^{*} \\
\text { Endereçado }\end{array}$ & 3 horas & $\begin{array}{l}\text { Trabalhar os pilares } \\
\text { do PC*: Algoritmo, } \\
\text { abstração, } \\
\text { decomposição e } \\
\text { reconhecimento de } \\
\text { padrões desta forma: } \\
\text { a) Escrita de um } \\
\text { algoritmo do } \\
\text { caminho de casa para } \\
\text { a escola; } \\
\text { b) Mapear o caminho } \\
\text { fisicamente através } \\
\text { de uma maquete. }\end{array}$ & $\begin{array}{l}\text { A proposta consiste em dividir as alunas em dois a três } \\
\text { grupos, e eleger uma das colegas para: } \\
\text { Primeira parte: escrita do algoritmo de ir de casa até a } \\
\text { escola; E a segunda parte: Mapear o caminho de casa até a } \\
\text { escola através de uma maquete. Inicialmente pretende-se } \\
\text { dividir as alunas, entre dois a três grupos, e o grupo deverá } \\
\text { escolher uma das pessoas para ser o modelo a ser utilizado } \\
\text { na construção do caminho de casa até a escola. Ao final da } \\
\text { oficina, deseja-se que as alunas tenham escrito o algoritmo } \\
\text { de ida até a escola, e também construído a maquete. Os } \\
\text { materiais, tais como isopor, cola, tinta, tesoura, papel } \\
\text { serão levados para garantir a execução da proposta. No } \\
\text { momento seguinte, a proposta é comparar o algoritmo com } \\
\text { a maquete, e refletir como algoritmo interferiu na } \\
\text { construção da maquete. }\end{array}$ \\
\hline
\end{tabular}




\begin{tabular}{|c|c|c|c|}
\hline $\begin{array}{l}\mathrm{PC}^{*} \\
\text { Divertido }\end{array}$ & 2 horas & $\begin{array}{l}\text { Trabalhar os pilares } \\
\text { do PC*: Algoritmo, } \\
\text { abstração, } \\
\text { decomposição e } \\
\text { reconhecimento de } \\
\text { padrões desta forma: } \\
\text { a) Brincar } \\
\text { efetivamente e } \\
\text { observar as } \\
\text { estratégias utilizadas; } \\
\text { b) Escrever o } \\
\text { algoritmo mais } \\
\text { eficiente para a } \\
\text { brincadeira proposta; } \\
\text { c) Testar o algoritmo } \\
\text { proposto. }\end{array}$ & 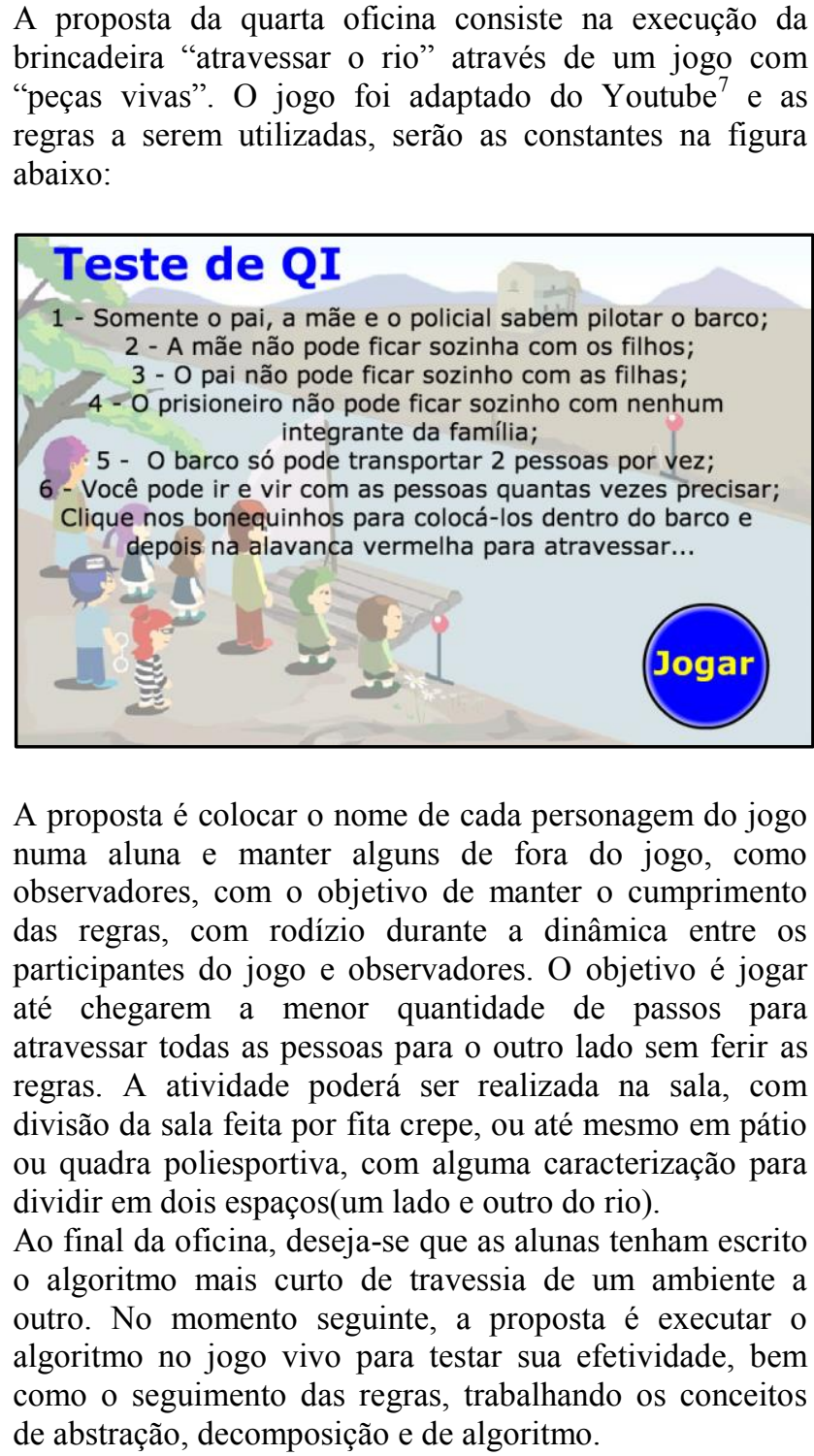 \\
\hline
\end{tabular}

*PC - Pensamento Computacional

Embora a proposta apresentada tenha como tema das oficinas assuntos social e culturalmente considerados "apenas femininos", o intuito é apenas partir desse ponto para iniciar a utilização do PC. Conforme previsão metodológica das oficinas, após execução das atividades previstas nas mesmas, haverá um momento que permitirá ao público da ação refletir sobre a resolução prática dos problemas frente a forma teórica, o que pode desencadear a criticidade para uma posterior transposição de técnicas de resolução de problemas em outras esferas. E no caso das meninas, conscientizando-as de que são capazes e de que é possível resolver problemas em quaisquer contextos, sendo possível adentrar, desbravar e potencializar a participação em diversas esferas sociais, cuja participação feminina ainda é minoria, e muitas vezes hostilizadas.

\footnotetext{
${ }^{7}$ https://www.youtube.com/watch?v=vu7qWbvnS4U
} 
VIII Congresso Brasileiro de Informática na Educação (CBIE 2019)

Anais dos Workshops do VIII Congresso Brasileiro de Informática na Educação (WCBIE 2019)

\section{Conclusão}

Considerando a versatilidade da utilização do pensamento computacional, que permite aplicação em diversos contextos, a proposta apresentada pode ser viável, pois apresenta a inovação no sentido de valorizar interesses do público alvo, através da resolução de problemas simples, reais e corriqueiros por meio da aprendizagem baseada em problemas.

Por se tratar de um trabalho em andamento, a intenção é que o material produzido seja disponibilizado de forma gratuita e acessível para que possa ser adaptado em outros contextos e temáticas, contribuindo para a disseminação do PC, via metodologias ativas.

Os trabalhos futuros a partir deste poderão ser propostas que tenham como fundamento o pensamento computacional sendo trabalhado de forma ativa, objetivando desenvolver as diversas habilidades cognitivas requeridas para aprendizagem da programação, considerando a realidade local, contexto e preferências do público em que a ação ocorrerá, uma vez que neste trabalho acredita-se que a participação ativa e decisão sobre os assuntos/práticas a serem abordados poderão conduzir diferentes objetivos a resultados satisfatórios nas mais variadas áreas.

\section{Referências}

Andrade, J. O. Neto, A. C.(Orgs).(2015). Mulheres profissionais e suas carreiras sem censura : estudos sob diferentes abordagens. São Paulo: Atlas.

Antunes, R. (2009). Os sentidos do trabalho: ensaio sobre a afirmação e a negação do trabalho. 2. ed. $10^{\mathrm{a}}$ reimpressão. São Paulo: Boitempo.

Antunes, C. (2001). Trabalhando habilidades: construindo ideias. São Paulo:Scipione.

Blatt, L.; Becker, V.; Ferreira, A.(2017). Mapeamento Sistemático sobre Metodologias e Ferramentas de apoio para o Ensino de Programação. In: Anais do Workshop de Informática na Escola(p. 815).

Brackmann, C. P.(2017). Desenvolvimento do pensamento computacional através de atividades desplugadas na educação básica. Porto Alegre.

Brasil. (2012). Ministério da Educação. Parecer Conselho Nacional de Educação Câmara de Educação Básica $n^{\circ} 11 / 2012$. Diretrizes Curriculares Nacionais para a Educação Profissional Técnica de Nível Médio.

Filatro, A. Cavalcanti, C. C. (2018) Metodologias Inov-Ativas na educação presencial, a distância e corporativa. 1.ed. São Paulo: Saraiva Educação.

Gomes, Wesckley Faria et al.(2014). Incentivando meninas do ensino médio à área de Ciência da Computação usando o Scratch como ferramenta. In: Anais do Workshop de Informática na Escola(p. 223).

Lima, M. P. (2013). As mulheres na Ciência da Computação. Estudos feministas. Florianópolis(p. 793-816).

Lopes, Anita. Garcia, Guto (2002). Introdução à programação: 500 algoritmos resolvidos. Rio de Janeiro: Elsevier.

Nunes, D. J. (2015). Educação Superior em Computação, Estatísticas 2015. Sociedade Brasileira de Computação-SBC. Disponível em: $<$ http://www. sbc. org. 
VIII Congresso Brasileiro de Informática na Educação (CBIE 2019)

Anais dos Workshops do VIII Congresso Brasileiro de Informática na Educação (WCBIE 2019)

$\mathrm{br} /$ documentos-da-sbc/summary/133-estatisticas/1074-educacaosuperior-emComputação-estatisticas-2015>. Acesso em 08 nov 2018.

Oliveira, M. G., Nogueira, M. D. A., \& Oliveira, E. (2015). Sistema de Apoio à Prática Assistida de Programação por Execução em Massa e Análise de Programas. In XIV Workshop de Educação em Computação (WEI)-SBC.

Paula, L. D., Piva Jr, D., \& Freitas, R. L. (2009). A Importância da Leitura e da Abstração do Problema no processo de formação do raciocínio lógico-abstrato em alunos de Computação. In XVII Workshop sobre Educação em Computação-WEI.

Queiroz, P., \& Santos, H. (2017). Contribuições do PIBID Interdisciplinar de Licenciatura em Computação e Pedagogia na Escola. In Anais do Workshop de Informática na Escola (Vol. 23, n . 1, p. 500).

Pinsky, C. B. Pedro, J. M. (Orgs.) (2012). Nova história das mulheres. 1 ed. São Paulo: Contexto.

Ramos, Nadja et al(2015). Ensino de programação para alunas de ensino médio: Relato de uma experiência. In: XXIII Anais do Workshop sobre Educação em Computação.

Ribeiro, L.; Foss, L.; Cavalheiro, S. A. C.(2017). Entendendo o Pensamento Computacional. In: arXiv preprint arXiv:1707.00338.

Saviani, D. (1994). O trabalho como princípio educativo frente às novas tecnologias. Novas tecnologias, trabalho e educação: um debate multidisciplinar. Petrópolis: Vozes, 147-164.

Schoeffel, Pablo et al(2015). Uma experiência no ensino de pensamento computacional para alunos do ensino fundamental. In: Anais dos Workshops do Congresso Brasileiro de Informática na Educação( p. 1474).

Toole, Betty Alexandra.(1998). Ada Lovelace Biography. Disponível em: $<$ http://www.well.com/user/adatoole/bio.htm $>$. Acesso em 14 mar 2019.

Wing, J. (2016). Pensamento Computacional-Um conjunto de atitudes e habilidades que todos, não só cientistas da computação, ficaram ansiosos para aprender e usar. Revista Brasileira de Ensino de Ciência e Tecnologia. 